\title{
Heat Capacity, Heats of Transitions, Fusion, and Vaporization, and Vapor Pressure of Octafluorocyclobutane
}

\author{
George T. Furukawa, Robert E. McCoskey, and Martin L. Reilly
}

\begin{abstract}
The heat capacity of octafluorocyclobutane of $99.98_{9}$-mole-percent purity was determined in an adiabatic calorimeter from $17^{\circ}$ to $270^{\circ} \mathrm{K}$. The heat of fusion is $2768.2 \pm 2.0$ abs j mole $\mathrm{e}^{-1}$ at the triple-point temperature of $232.96 \pm 0.05^{\circ} \mathrm{K}$. The three heat-of-vaporization experiments at the vapor pressure of $590.9 \mathrm{~mm} \mathrm{Hg}$ and $261.25^{\circ} \mathrm{K}$ gave an average value of $23721 \pm 20$ abs $\mathrm{j}$ mole ${ }^{-1}$. Four solid-solid transitions were observed with the heatcapacity peaks at $141.3 \pm 0.2^{\circ}, 174.6 \pm 0.2^{\circ}, 214.84 \pm 0.05^{\circ}$, and $216.99 \pm 0.05^{\circ} \mathrm{K}$. The anomalous behavior in the heat capacity at about $97^{\circ} \mathrm{K}$, where the heat capacity changes its slope abruptly, is attributed to glass transformation. The vapor pressure was measured from $177^{\circ}$ to $274^{\circ} \mathrm{K}$. The results of this measurement from the triple-point temperature to $274^{\circ} \mathrm{K}$ can be represented within $\pm 0.5 \mathrm{~mm} \mathrm{Hg}$ in most cases by the equation

$$
\log _{10} p(\mathrm{~mm} \mathrm{Hg})=6.70267-\frac{1315.906}{T}+8.778482 \times 10^{-3} T-1.739691 \times 10^{-5} T^{2} .
$$

The entropy of octafluorocyclobutane in the ideal gas state at $261.25^{\circ} \mathrm{K}$ and $1 \mathrm{~atm}$ was computed from the experimental data to be $380.52 \pm 0.71 \mathrm{abs} \mathrm{j} \mathrm{deg}^{-1}$ mole $^{-1}$ or $90.95 \pm 0.17$ cal $\mathrm{deg}^{-1} \mathrm{~mole}^{-1}(1 \mathrm{cal}=4.1840 \mathrm{abs} \mathrm{j})$. The entropy computed from the spectroscopic assignments by Claassen and the molecular constants based on the $\mathrm{D}_{4 \mathrm{~h}}$ model amounted to 87.83 cal deg ${ }^{-1} \mathrm{~mole}^{-1}$.
\end{abstract}

\section{Introduction}

Octafluorocyclobutane can be prepared by pyrolysis of polytetrafluoroethylene ${ }^{2}$ and by cyclic dimerization of tetrafluoroethylene. ${ }^{3}$ The latter material has come into importance in the recent years as the monomer in the production of polytetrafluoroethylene plastic (Teflon), which has a remarkably high chemical and thermal stability. In order to obtain a wider thermodynamic knowledge regarding the fluorocarbons, fluorocarbon polymers, and monomers or prototype molecules, calorimetric and vaporpressure measurements have been made with octafluorocyclobutane. This material is interesting also from the viewpoint of its structure; some ${ }^{45}$ of the investigators have interpreted its vibrational spectra in terms of a planar ring model $\left(\mathrm{D}_{4 \mathrm{~h}}\right)$. More recent spectral ${ }^{6}$ and electron diffraction ${ }^{7}$ studies seem to favor the nonplanar ring structure $\left(\mathrm{V}_{\mathrm{d}}\right)$. There is at present an investigation being conducted at the Bureau to make spectral assignments in light of the evidence for a $V_{d}$ structure.

Calorimetric studies with the tetrafluoroethylene ${ }^{8}$ and the polytetrafluoroethylene ${ }^{9}$ have been reported recently by the National Bureau of Standards.

\footnotetext{
This paper is based on research sponsored by the Ordnance Corps, U. S Department of the Army.

United States Patent 2384821

3 United States Patent 2404374.

4 W. F. Edgell, J. Am. Chem. Soc. 69, 660 (1947).

${ }^{4}$ W. F. Edgell, J. Am. Chem. Soc. 69, $660(1947)$

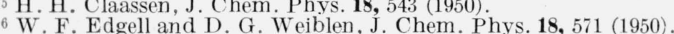

W. F. Edgell and D. G. Weiblen, J. Chem. Phys. 18, 571 (1950).
7 H. P. Lemaire and R. L. Livingston, J. Chem. Phys. 18, $569(1950)$

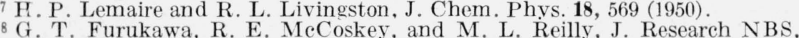
51. (1953) RP2432.

51, (1953) RP2432.

273 (1952) RP2364.
}

\section{Apparatus and Method}

The heat-capacity, the heat-of-fusion, and the vapor-pressure measurements with the octafluorocyclobutane were carried out in the adiabatic calorimeter described previously by R. B. Scott, et al. ${ }^{10}$

For the vapor-pressure measurements the calorimeter valve was opened to a mercury manometer, which was read by means of a mirror-backed glass scale. The calorimeter served as a thermostated container. No provision was made to stir the sample. The pressure readings were converted to standard $\mathrm{mm} \mathrm{Hg}\left(g=980.665 \mathrm{~cm} \mathrm{sec}^{-2}\right.$, temperature $=0^{\circ}$ C.) on the basis that the local gravity is $980.076 \mathrm{~cm} \mathrm{sec}^{-2}$.

The heat-of-vaporization measurements were made in another adiabatic calorimeter similar in design to those described by Osborne and Ginnings ${ }^{11}$ and by Aston, et al. ${ }^{12}$ This calorimeter contained a throttle valve within the space enclosed by the adiabatic shield. During the vaporization experiments, the vapor was removed isothermally by controlling the valve and introducing a known electric energy continuously. A nickel resistance thermometer wound on the tube between the valve and the calorimeter container served to sense the temperature of the vapor removed. When a desired quantity of the material was collected, the electric power was cut off and the valve closed. The heat of vaporization per mole, $L$, was computed from the total energy

${ }^{10}$ R. B. Scott, C. H. Meyers, R. D. Rands, Jr., F. G. Brickwedde, and N. Bekkedahl, J. Research NBS 35, 39 (1945) RP1661.

11 N.S. Osborne and D. C. Ginnings, J. Research NBS 39, 453 (1947) RP1841. 12 J. G. Aston, H. L. Fink, G. J. Janz, and K. E. Russell, J. Am. Chem. Soc. 73, 1939 (1951). 
nput, $Q$, and the mass, $m$, of material collected by the relation

$$
L=\frac{M Q}{m}\left(1-\frac{u}{u^{\prime}}\right)
$$

in which $u$ and $u^{\prime}$ are the specific volumes of the liquid and vapor, respectively, at the vaporization temperature and $M$ is the molecular weight.

All temperature measurements are in accordance with the International Temperature Scale ${ }^{13}$ and below $90^{\circ} \mathrm{K}$ in accordance with a provisional scale ${ }^{14}$ based on a set of platinum resistance thermometers calibrated against a helium-gas thermometer.

\section{Material}

The octafluorocyclobutane used in this investigation was kindly furnished by the E. I. du Pont de Nemours \& Co. Although the sample was considered quite pure, the possible impurities were tetrafluoroethylene $\left(\mathrm{C}_{2} \mathrm{~F}_{4}\right)$ and chlorodifluoromethane $\left(\mathrm{CHClF}_{2}\right)$. The material was purified further by fractional crystallization. The procedure was similar to that described by Schwab and Wichers. ${ }^{15}$ The purity of the material so treated was determined prior to the heat-capacity experiments from the equilibrium melting temperatures ${ }^{16}$ and was found to be $99.98_{9}$ mole percent. The equilibrium temperatures and the corresponding reciprocal of the fraction melted, $F$, are given in table 1 . The triple-point temperature (obtained by extrapolating the temperature versus $1 / F$ plot to $1 / F=0$ ) was found to be $232.96 \pm 0.05^{\circ} \mathrm{K}$. (In this paper, unless defined otherwise, the figure following the plus or minus is the authors' best estimate of the uncertainty.) A second purity measurement at the end of the heatcapacity studies gave essentially the same result.

TABLE 1. Equilibrium melting temperatures of octafluorocyclobutane

Mole fraction impurity $=0.00613 \Delta T$, ${ }^{\circ} \mathrm{K}=273.16+{ }^{\circ} \mathrm{C}$

\begin{tabular}{|c|c|}
\hline $\begin{array}{c}\text { Reciprocal of } \\
\text { fraction } \\
\text { melted, } 1 / F\end{array}$ & $T$ \\
\hline & ${ }^{\circ} K$ \\
12.74 & a 232.7587 \\
8.33 & 232.8012 \\
6.74 & 232.8215 \\
3.93 & 232.8676 \\
2.05 & 232.9114 \\
1.55 & 232.9278 \\
1.22 & 232.9420 \\
0.00 & b 232.9580 \\
\hline \multicolumn{2}{|c|}{} \\
Triple-point & temperature, \\
$232.96 \pm 0.05^{\circ}$ & K. Purity, \\
99.989 & mole percent. \\
\hline
\end{tabular}

a The temperatures given are accurate to $\pm 0.01^{\circ} K$. Wherever temperatures are given to the fourth decimal, the last two figures are significant only insofar as small temperature differences are concerned.

b Extrapolated.

${ }^{13}$ H. F. Stimson, J. Research N BS 42, 209 (1949) RP1962.

${ }_{14}$ H. J. Hoge and F. G. Brickwedde, J. Research NBS 22, 351 (1939) RP1188.

$15 \mathrm{~F}$. W. Schwab and E. Wichers, J. Research NBS 32, 253 (1944) R P588.

16 G. T. Furukawa, D. C. Ginnings, R. E. MeCoskey, and R. A. Nelson, J. Research NBS 46, 195 (1951) RP2191.
In these purity determinations the system was assumed to behave ideally and to form no solid solution.

\section{Heat Capacity}

The heat-capacity measurements were carried out from $17^{\circ}$ to $270^{\circ} \mathrm{K}$. The observed values are given in table 2 and are also plotted in figure 1 to show the four solid-solid transitions observed. The temperatures given in the table are the mean temperatures of heating intervals. The temperature rise associated with each heating interval is also given. The corresponding heat-capacity values, which are under conditions of saturation have been corrected for curvature (see footnote 16) and vapor saturation ${ }^{17}$ wherever applicable.

The heat capacity in the temperature range of each transition was carefully investigated. Of the four solid-solid transitions, two were found very close together, similar to those in hydrogen bromide. ${ }^{18}$ Equilibrium was attained within these two transitions $\left(214.84^{\circ}\right.$ and $216.99^{\circ} \mathrm{K}$ ) in the usual time of 6 to $10 \mathrm{~min}$. On the other hand, the relaxation time for the transitions at the two lower temperatures $\left(141.3^{\circ}\right.$ and $\left.174.6^{\circ} \mathrm{K}\right)$ was found to be extremely long; small but definite temperature drifts were observed even $2 \mathrm{hr}$ after the end of heating. On account of this long relaxation time, the heat capacity in these transition ranges was dependent somewhat upon the thermal history or the rate of cooling prior to the experiments. Thus, the results in the transition region are scattered, up to as much as 0.3 percent. The peaks of the heat capacities within the four transitions were found to be $141.3 \pm 0.2^{\circ}$, $174.6 \pm 0.2^{\circ}, 214.84 \pm 0.05^{\circ}$, and $216.99 \pm 0.05^{\circ} \mathrm{K}$. The heat of transition was not determined for any given temperature; instead, the enthalpy change was determined for an interval of convenient temperatures, which included the transition. These results are given in section 5 .

Figure 1 shows an anomalous behavior in the region of $97^{\circ} \mathrm{K}$, in which the heat capacity under goes a rather abrupt change in slope. Also, a longer time (about $30 \mathrm{~min}$ ) was required for temperature equilibrium. A magnified plot of this temperature range is shown in figure 2 . The cooling rate prior to the heat-capacity measurements had a decided effect upon the results in this temperature range. Slow cooling yielded significantly higher values. As pointed out in section 5 , the increase in the enthalpy change corresponding to the higher heat-capacity values in this temperature range seems to be offset by an almost equal enthalpy change decrease in the interval $130^{\circ}$ to $150^{\circ} \mathrm{K}$.

Although not as pronounced, the heat-capacity behavior of the substance near $97^{\circ} \mathrm{K}$ is similar to the glass transformation found in organic glasses, ${ }^{19}$ high polymers ${ }^{20}$ and other noncrystalline solids. Similar

${ }_{17}$ H. J. Hoge, J. Research NBS 36, 111 (1946) RP1693.

18 W. F. Giauque and R. W. Wiebe, J. Am. Chem. Soc. 50, 2193 (1928),

19 G. S. Parks, H. M. Huffman, and F. R. Cattoir, J. Phys. Chem. 32, 1366 (1928).

${ }_{20}^{20}$ G. T. Furukawa, R. E. MeCoskey, and G. J. King, J. Researeh NBS 50, 357 (1953) RP2425. 
TABLE 2. Observed molal heat capacities of octafluorocyclobutane

Molecular weight $=200.04 ;{ }^{\circ} \mathrm{K}=273.16+{ }^{\circ} \mathrm{C}$

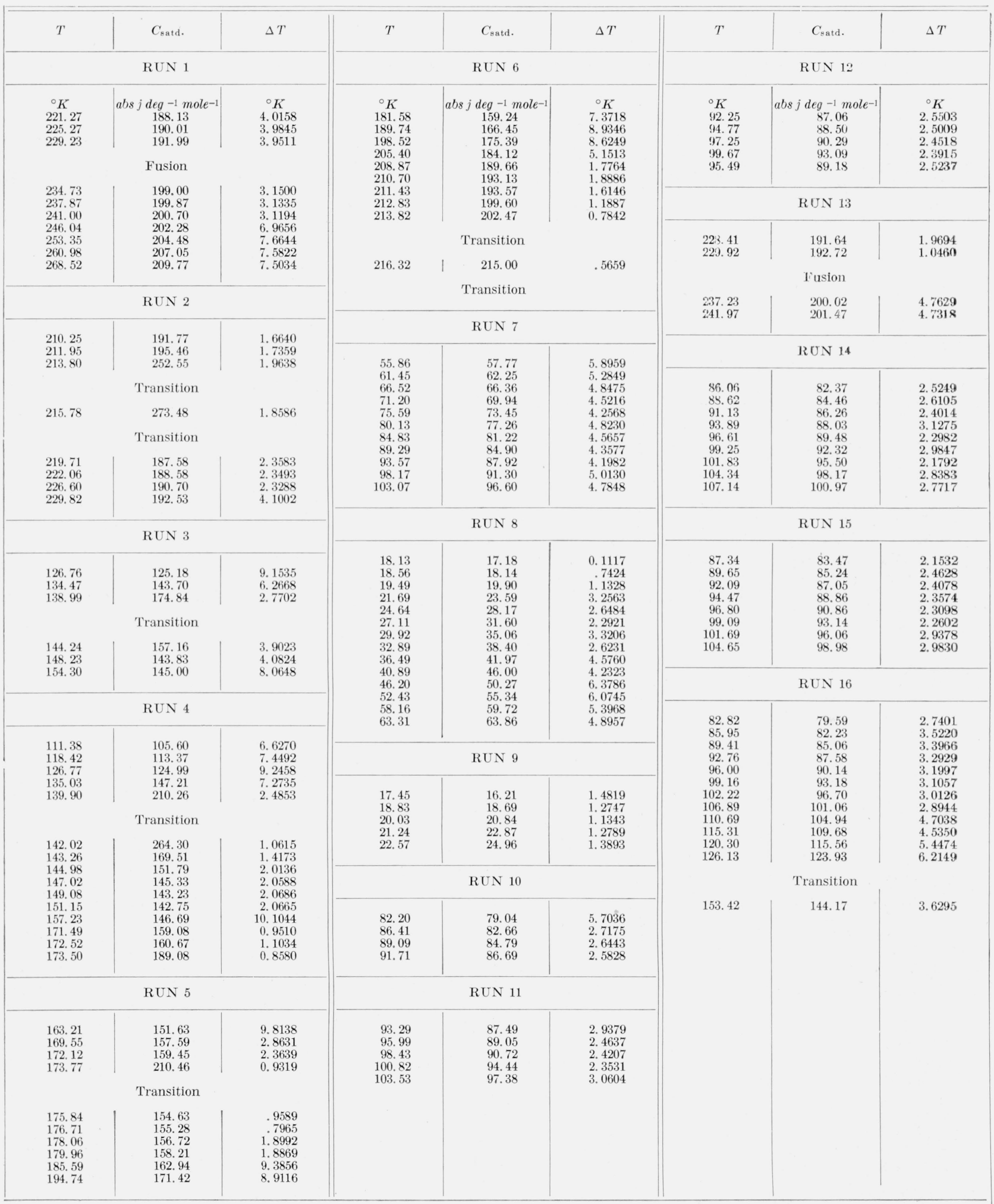




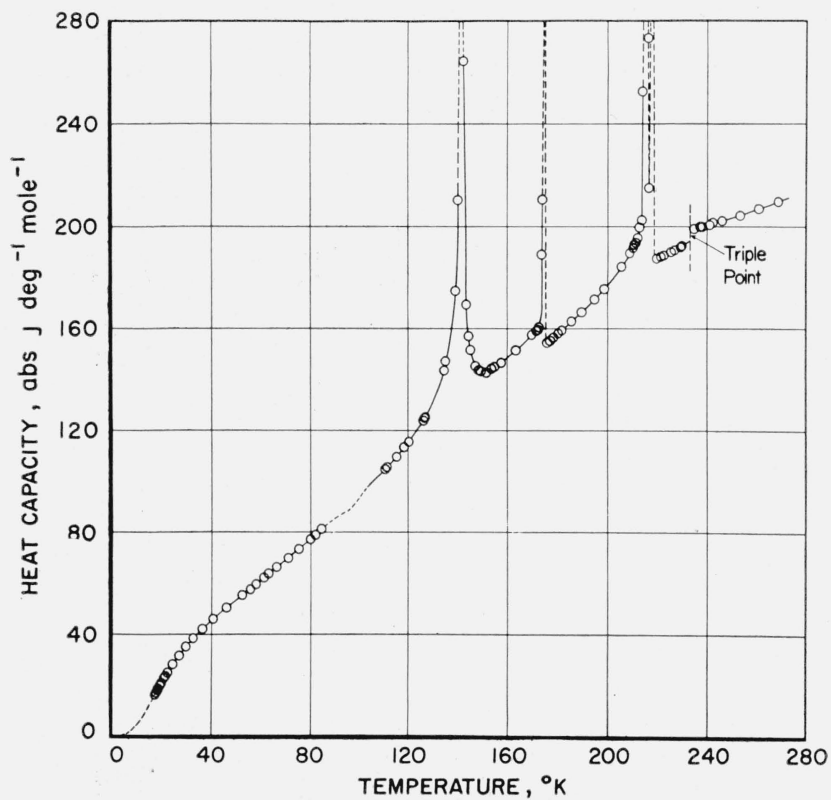

Figure 1. Observed heat capacities of octafluorocyclobutane.

behavior was reported by Huffman, et al. ${ }^{21}$ for cyclopentene and other compounds.

The heat-capacity values given in table 2 are probably accurate to 0.2 percent, except in the transition regions of $141.3^{\circ}$ and $174.6^{\circ} \mathrm{K}$, the anomalous region of $97^{\circ} \mathrm{K}$, and the temperature range below $50^{\circ} \mathrm{K}$, where larger tolerances must be allowed.

\section{Heats of Fusion and Transitions}

The heat of fusion was determined in the usual manner by introducing a known electric energy from a temperature just below the triple point to just above it and correcting for the premelting and heat capacity. The results of three measurements are summarized in table 3 . The values given in the fourth column are the total heats required to melt $141.9302 \mathrm{~g}$ of the sample in the calorimeter. Considering the precision of the measurements and various sources of error, the uncertainty of the heat of fusion is believed to be \pm 2.0 abs $\mathrm{j} \mathrm{mole}^{-1}$.

TABLE 3. Molal heat of fusion of octafluorocyclobutane

Molecular weight - 200.04; mass of sample-141.9302 g; triple-point temperature $=$ $232.96^{\circ} \mathrm{K} ;{ }^{\circ} \mathrm{K}=273.16+{ }^{\circ} \mathrm{C}$

\begin{tabular}{|c|c|c|c|c|}
\hline Temperature interval & Heat input & $\begin{array}{l}\text { Heat capac- } \\
\text { ity and } \\
\text { premelting } \\
\text { correction }\end{array}$ & $\Delta H$ & $\Delta H_{f}$ \\
\hline $\begin{array}{l}{ }^{\circ} K \\
227.6435 \text { to } 237.3363 \\
227.7655 \text { to } 234.7512 \\
227.4253 \text { to } 234.8109\end{array}$ & $\begin{array}{c}a b s j \\
4199.9 \\
3567.3 \\
3657.7\end{array}$ & $\begin{array}{l}a b s j \\
2236.9 \\
1602.2 \\
1693.9\end{array}$ & $\begin{array}{c}a b s j \\
1963.0 \\
1965.1 \\
1963.8\end{array}$ & $\begin{array}{c}a b s j \text { mole } \\
2766.7 \\
2769.8 \\
2768.0\end{array}$ \\
\hline $\begin{array}{l}\text { Mean heat of fusion. } \\
\text { Standard deviation. }\end{array}$ & & & & $\begin{array}{r}2768.2 \\
\pm 0.7\end{array}$ \\
\hline
\end{tabular}

${ }^{21}$ H. M. Huffman, M. Eaton, and G. D. Oliver, J. Am. Chem. Soc. 70, 2911 (1948).

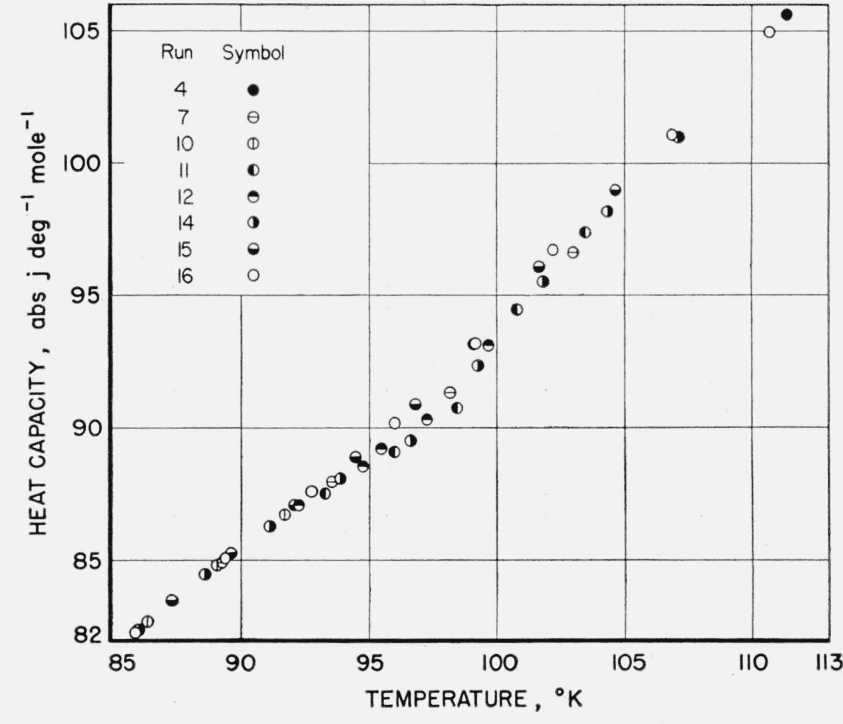

Figure 2. Observed heat capacities of octafluorocyclobutane from $85^{\circ}$ to $113^{*} \dot{K}$.

TABLE 4. Molal enthalpy changes over even temperature intervals, including the solid-solid transitions and the anomalous region

Molecular weight $=200.04 ;{ }^{\circ} \mathrm{K}=273.16+{ }^{\circ} \mathrm{C}$

\begin{tabular}{|c|c|c|c|}
\hline Temperature interval & $\begin{array}{l}\text { Total energy } \\
\text { input }\end{array}$ & $\begin{array}{l}\text { Heat capacity } \\
\text { correction }\end{array}$ & $\Delta H$ \\
\hline \multicolumn{4}{|c|}{$H_{153^{\circ} \mathrm{K}}-H_{130^{\circ} \mathrm{K}}$} \\
\hline \multirow[t]{2}{*}{$\begin{array}{c}{ }^{\circ} \mathrm{K} \\
122.1832 \text { to } 150.27255^{\mathrm{a}} \\
133.2603 \text { to } 150.6635 \text { b..... }\end{array}$} & \multirow[t]{2}{*}{$\begin{array}{l}\text { abs j mole } \text { mol }^{-1} \\
5095.7 \\
3739.7\end{array}$} & \multirow{2}{*}{$\begin{array}{c}\text { abs j mole } e^{-1} \\
\quad-1010.0 \\
\quad+346.0 \\
\text { Mean }\end{array}$} & $\begin{array}{l}\text { abs } j \text { mole } e^{-1} \\
\quad 4085.7 \\
\quad 4085.7\end{array}$ \\
\hline & & & 4085.7 \\
\hline 129.2400 to 151.6058 b c & 4405.2 & -328.8 & 4076.4 \\
\hline \multicolumn{4}{|c|}{$H_{180^{\circ} \mathrm{\kappa}}-H_{170^{\circ} \mathrm{\kappa}}$} \\
\hline \multirow[t]{2}{*}{$\begin{array}{l}170.9367 \text { to } 180.8963 \mathrm{a} \\
168.7525 \text { to } 177.23411^{\mathrm{b}}\end{array}$} & \multirow[t]{2}{*}{$\begin{array}{l}5002.3 \\
4768.1\end{array}$} & \multirow{2}{*}{$\begin{array}{r}+6.0 \\
+237.8 \\
\text { Mean } \\
\end{array}$} & $\begin{array}{l}5008.3 \\
5005.9\end{array}$ \\
\hline & & & 5007.1 \\
\hline \multicolumn{4}{|c|}{$H_{220^{\circ} \mathrm{K}}-H_{210^{\circ} \mathrm{K}}$} \\
\hline \multirow[t]{2}{*}{$\begin{array}{l}209.4137 \text { to } 220.8877 \text { a } \\
212.4227 \text { to } 222.1278 \text { b- }\end{array}$} & \multirow[t]{2}{*}{$\begin{array}{l}4878.4 \\
4529.9\end{array}$} & \multirow{2}{*}{$\begin{array}{r}-278.9 \\
+70.0 \\
\text { Mean }\end{array}$} & $\begin{array}{l}4599.5 \\
4599.9\end{array}$ \\
\hline & & & 4599.7 \\
\hline \multicolumn{4}{|c|}{$H_{105^{\circ} \mathrm{K}}-H_{90^{\circ} \mathrm{K}}$} \\
\hline \multirow[t]{2}{*}{$\begin{array}{l}87.1084 \text { to } 105.46211^{\mathrm{a}} \\
89.9824 \text { to } 105.757 \mathrm{a}^{\mathrm{a}}\end{array}$} & \multirow[t]{2}{*}{$\begin{array}{l}1659.0 \\
1450.4\end{array}$} & \multirow{4}{*}{$\begin{array}{c}-289.9 \\
-81.2 \\
\text { Mean_- } \\
-247.7 \\
-67.3 \\
\text { Mean }\end{array}$} & $\begin{array}{l}1369.1 \\
1369.2\end{array}$ \\
\hline & & & 1369.2 \\
\hline \multirow[t]{2}{*}{$\begin{array}{l}88.4184 \text { to } 106.1372 \text { a }{ }^{\mathrm{c}}- \\
87.7140 \text { to } 103.7215 \text { a } \mathrm{c}-\end{array}$} & \multirow[t]{2}{*}{$\begin{array}{l}1626.9 \\
1446.5\end{array}$} & & $\begin{array}{l}1379.2 \\
1379.2\end{array}$ \\
\hline & & & 1379.2 \\
\hline
\end{tabular}

a Heated in increments over this temperature interval under adiabatic con.

ditions. ditions.

c The sample was cooled slowly over 1 week from $230^{\circ}$ to $80^{\circ} \mathrm{K}$ prior to the heat-capacity measurements. 
As mentioned in section 4 , in the temperature range of the four solid-solid transitions, small increments of heat were added to obtain the shape of the heat-capacity curve. Instead of attempting to determine the heat of transition at a given temperature, the enthalpy change was determined over an interval of convenient temperatures. This was done both by summing the increments of heats added in the determination of the shape of the heat-capacity curve and by heating continuously through this interval. The results of both experimental methods are summarized in table 4 . The values given in the third column are corrections used to reduce the enthalpy changes to the even temperature intervals indicated. The anomalous region was treated in a similar manner by summing the heats added in the interval from $90^{\circ}$ to $105^{\circ} \mathrm{K}$. In one series of measurements (see table 2 , runs 15 and 16 ), the material was cooled slowly over a period of 1 week from $230^{\circ}$ to $80^{\circ} \mathrm{K}$. The enthalpy change, as well as the heat capacity in the interval $90^{\circ}$ to $105^{\circ} \mathrm{K}$, was higher. The enthalpy change from $90^{\circ}$ to $105^{\circ} \mathrm{K}$ was 10.0 abs j mole ${ }^{-1}$ higher. Also, there was found a decrease in the enthalpy change in the interval $130^{\circ}$ to $150^{\circ} \mathrm{K}$ of 9.3 abs $\mathrm{j} \mathrm{mole}^{-1}$.

\section{Heat of Vaporization}

Three heat of vaporization experiments were made at $261.25^{\circ} \mathrm{K}(p=590.9 \mathrm{~mm} \mathrm{Hg})$. The experimentally observed quantity, $M Q / m$, the conversion factor, $1-u / u^{\prime}$, and the heat of vaporization, $L$, are given in table 5 . The specific volumes, $u$ and $u^{\prime}$, for this material were kindly furnished by the E. I. du Pont de Nemours \& Co. Considering the precision obtained and various sources of error, the uncertainty of the heat-of-vaporization value is believed to be \pm 20 abs $\mathrm{j}$ mole ${ }^{-1}$.

\section{TABLE 5. Molal heat of vaporization of octafluorocyclobutane at $261.25^{\circ} \mathrm{K}$}

Pressure $=590.9 \mathrm{~mm} \mathrm{Hg}$; molecular weight $=200.04 ;{ }^{\circ} \mathrm{K}=273.16+{ }^{\circ} \mathrm{C}$

\begin{tabular}{|c|c|c|}
\hline MQ/m & $1-u / u^{\prime}$ & $L$ \\
\hline & & \\
\hline abs j mole & & abs j mole $e^{-1}$ \\
23,842 & 0.99550 & 23,735 \\
23,823 & .99550 & 23,716 \\
23,818 & .99550 & 23,711 \\
& & 23,721 \\
\hline Mean & \pm 6 \\
Standard deviation...... & \\
\hline
\end{tabular}

\section{Vapor Pressure}

As there was no provision made to stir the sample, several series of vapor-pressure measurements were made under different conditions io make certain that temperature equilibrium was attained. The measurements were made going down the temperature scale as well as up. The close agreement in the results given in table 6 indicates that good temperature equilibrium existed. The results above the triple-point temperature $\left(232.96^{\circ} \mathrm{K}\right)$ were fitted to an equation given by

$$
\begin{aligned}
& \log _{10} p(\mathrm{~mm} \mathrm{Hg})=6.70267-\frac{1315.906}{T} \\
& +8.778482 \times 10^{-3} T-1.739691 \times 10^{-5} T^{2} .
\end{aligned}
$$

The observations are compared with this equation in table 6 . The equation gives the normal boiling temperature as $267.17 \pm 0.01^{\circ} \mathrm{K}$ and the triple-point pressure as $142.8 \pm 0.3 \mathrm{~mm} \mathrm{Hg}$.

TABLE 6. Vapor pressure of octafluorocyclobutane

\begin{tabular}{|c|c|c|c|c|c|c|c|}
\hline$T_{\text {obs. }}$ & $p_{\text {obs. }}$ & $p_{\text {cale. }}$ & $p_{\text {obe. }}-p_{\text {eale }}$ & $T_{\text {obs. }}$ & $p_{\text {obs. }}$ & $p_{\text {calc. }}$ & $p_{\text {obs. }}-p_{\text {cale }}$ \\
\hline \multicolumn{4}{|c|}{ Series I } & ${ }^{\circ} \mathrm{K}$ & $m m$ & $m m$ & $m m \mathrm{Hg}$ \\
\hline $\begin{array}{c}{ }^{\circ} \mathrm{K} \\
267.89 \\
270.95 \\
273.63\end{array}$ & $\begin{array}{c}\text { pand } \\
m m \text {. } \\
\mathrm{Hg} \text {. } \\
782.6 \\
886.2 \\
984.8\end{array}$ & \begin{tabular}{|l} 
T $\mathrm{mm}^{\text {7 }}$ \\
$\mathbf{1} \mathrm{Hg}$ \\
782.9 \\
885.9 \\
984.2
\end{tabular} & $\begin{array}{r}\int_{4 m} \mathrm{Hg} \\
-0.3 \\
-3 \\
-6\end{array}$ & $\begin{array}{l}241.32 \\
246.99 \\
253.01 \\
259.51 \\
263.88 \\
266.65\end{array}$ & $\begin{array}{l}226.3 \\
303.3 \\
406.5 \\
547.3 \\
661.9 \\
743.7\end{array}$ & $\begin{array}{l}226.5 \\
303.3 \\
406.5 \\
547.6 \\
662.2 \\
743.9\end{array}$ & $\begin{array}{r}-.2 \\
.0 \\
.0 \\
-.3 \\
-.3 \\
-.2\end{array}$ \\
\hline \multicolumn{4}{|c|}{ Series II } & \multicolumn{4}{|c|}{ Series III } \\
\hline $\begin{array}{l}179.16 \\
191.94 \\
201.23 \\
215.30 \\
223.60 \\
230.81 \\
232.91 \\
233.16\end{array}$ & $\begin{array}{r}5.0 \\
8.2 \\
14.7 \\
43.4 \\
77.7 \\
125.7 \\
142.4 \\
144.6\end{array}$ & $\begin{array}{c}\cdots- \\
\cdots \\
\cdots- \\
\cdots- \\
-\cdots \\
142.5 \\
144.5\end{array}$ & $\begin{array}{r}-0.1 \\
.1\end{array}$ & $\begin{array}{l}177.36 \\
191.82 \\
196.86 \\
197.17 \\
206.70 \\
213.09 \\
221.60 \\
271.94\end{array}$ & $\begin{array}{r}4.9 \\
8.2 \\
10.9 \\
11.0 \\
21.7 \\
35.9 \\
67.7 \\
921.4\end{array}$ & $\begin{array}{c}-- \\
-\cdots \\
-\cdots \\
-- \\
-- \\
-- \\
921.3\end{array}$ & 0.1 \\
\hline
\end{tabular}
${ }^{\circ} \mathrm{K}=273.16+{ }^{\circ} \mathrm{C}$

\section{Experimental Entropy}

The experimental data were used to calculate the entropy of the octafluorocyclobutane in the ideal gas state at $261.25^{\circ} \mathrm{K}$ and $1 \mathrm{~atm}$. The results of the various calculations are summarized in table 7 . In the temperature intervals in which the transitions occurred, the entropy change was evaluated by suming the various experimentally observed $C \Delta T / T$ 's, where $C$ is the observed heat capacity, $\Delta T$ the temperature rise, and $T$ the midtemperature of the heating interval. The entropy change so obtained was corrected to the even temperatures indicated in table 7. Below $180^{\circ} \mathrm{K}$, the results from the slowcooling experiments were used to evaluate the en-

TABLE 7. Summary of the experimental molal entropy of octafluorocyclobutane

Molecular weight $=200.04 ;{ }^{\circ} \mathrm{K}=273.16+{ }^{\circ} \mathrm{C}$

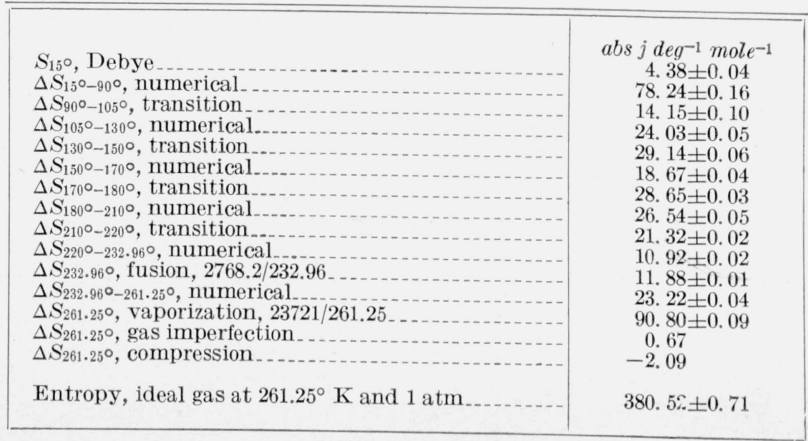


tropy. The gas-imperfection correction was computed on the assumption that the octafluorocyclobutane vapor can be represented by the Berthelot equation of state. The critical constants used were those reported by Renfrew and Lewis. ${ }^{22}$

The uncertainties given in table 7 were based on the precision, the probable nonreproducibility of the physical state below $180^{\circ} \mathrm{K}$, and various other sources of error. The absolute entropy obtained is probably in error by more than is given in the table because the results of the measurements indicate a certain degree of glassy state or randomness in the solid at the lower extreme of our measurements.

\section{Entropy From Molecular and Spectro- scopic Data}

The entropy of the gaseous octafluorocyclobutane was computed from the molecular and spectroscopic data based on the $\mathrm{D}_{4 \mathrm{n}}$ structure. The results are summarized and compared with the calorimetric entropy in table 8 . The rotational entropy was computed directly from the principal moments of inertia given by Smith, et al. ${ }^{23}$ in which the $\mathrm{C}-\mathrm{C}$ and $\mathrm{C}-\mathrm{F}$ bond distances and $\mathrm{C}-\mathrm{C}-\mathrm{C}$ and $\mathrm{F}-\mathrm{C}-\mathrm{F}$ angles were $1.53 \mathrm{~A}$ and $1.36 \mathrm{~A}$ and $90 \mathrm{dag}$. and 112

${ }_{22}^{2}$ M. M. Renfrew and E. E. Lewis, Ind. Eng. Chem. 38, 870 (1946)

23 D. C. Smith, J. R. Nielsen, L. H. Berryman, H. H. Claassen, and R. L. deg., respectively. The moments of inertia wer $^{\mathrm{e}}$ $I_{x}=I_{y}=796 \times 10^{-40} \mathrm{~g}-\mathrm{cm}^{2}$ and $I_{z}=951 \times 10^{-40} \mathrm{~g}-\mathrm{cm}^{2}$. The vibrational entropy was calculated on the basis of the assignments by Classen (see footnote 5).

On the basis of the existence of residual entropy in the calorimetric work, the discrepancy in the two results given in table 8 would be increased. Work is now in progress at the Bureau for the reassignment of the frequencies on the basis of the recent evidence for a $V_{d}$ structure.

TABLE 8. Molal entropy of octafluorocyclobutane at $261.25^{\circ} \mathrm{K}$ from molecular and spectroscopic data

Molecular weight $=200.04 ;{ }^{\circ} \mathrm{K}=273.16+{ }^{\circ} \mathrm{C} ; 1 \mathrm{cal}=4.1840 \mathrm{abs} \ldots$

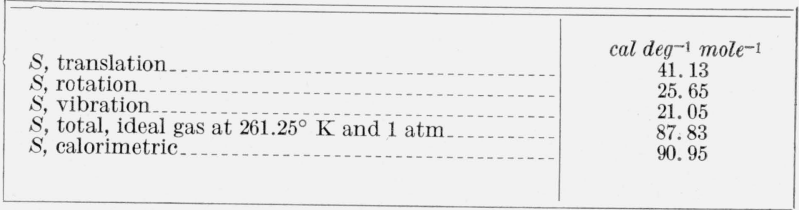

The authors are indebted to E. I. Du Pont de Nemours \& Co. for the sample of purified octafluorocyclobutane.

Washington, July 24, 1953. 